\title{
PERUBAHAN SIFAT FISIKA KIMIA KOPI ROBUSTA ASAL SEMENDO PADA BERBAGAI LEVEL PENYANGRAIAN
}

\section{CHANGE ON THE PHYSICAL AND CHEMICAL PROPERTIES OF ROBUSTA COFFEE FROM SEMENDO AT VARIOUS ROASTING LEVELS}

\author{
Sri Agustini ${ }^{1}$ \\ ${ }^{1}$ Balai Riset dan Standardisasi Industri Palembang \\ Jalan Kolonel H. Palembang, Sumatera Selatan, Indonesia 30152 \\ Correspondence: No HP +6281532898196, Fax: +62711412482 \\ e-mail: sragustini@yahoo.com
}

Diterima: 24 April 2020; Direvisi:18 Juni 2020; Disetujui: 18 Juni 2020

\begin{abstract}
Abstrak
Penelitian ini bertujuan untuk mempelajari perubahan sifat fisika kimia kopi robusta asal Semendo pada berbagai level penyangraian (roasting), dan untuk mengetahui karakter sifat fisika kimia kopi roasted. Penelitian dilakukan menggunakan rancangan acak lengkap dengan level roasting sebagai perlakuan. Sifat fisika kimia yang diamati adalah kadar air, volume, densitas, kehilangan berat, dan $\mathrm{pH}$ diukur menggunakan metode gravimetri. Warna diukur menggunakan Konica Minolta Color Reader yang dinyatakan dalam parameter L* (Comission Internationale de Eclairage), kadar kafein diuji menggunakan GC_MS, serta pengamatan perubahan karakter spektra kopi menggunakan FTIR. Hasil penelitian menunjukkan bahwa nilai parameter L kopi roasted antara $42,10 \pm 0,7-38,14 \pm 2,9$, kadar air antara 4,3 $\pm 0,7 \%-1,8 \pm 0,3 \%$, kehilangan berat $17,76 \pm 1,3 \%-19,02 \pm 0,9 \%$, Volume $40,7 \pm 2,1-57,67 \pm 2,3 \mathrm{ml}$, kadar kafein $2,39 \pm 0,1 \%-2,38 \pm 0,2 \%, \mathrm{pH} 6,6 \pm 0,7-6,2 \pm 0,2$. Level roasting berpengaruh terhadap karakter, sifat fisika kimia dan spektra kopi roasted.
\end{abstract}

Kata kunci : kopi Semendo, level roasting, Robusta,sifat fisika-kimia, spektra IR,

\begin{abstract}
The research intended to study the change on the physical and chemical properties of robusta coffee originated from Semendo at various roasting levels. The research was designed by using a completely randomized design with the roasting levels as a treatment. The physical and chemical properties observed are moisture content, volume, density, weight loss and $\mathrm{pH}$ determined by gravimetric method. The colour parameters is measured by using Konica Minolta Colour Reader expressed as $L^{*}$ parameter (Comission Internatiole de Eclairage). The caffeine content was determined using GC-MS. The change on spectral characteristic investigated by FTIR. The result showed that the $L$ value of roasted coffee ranged between $42.10 \pm 0.7-38.14 \pm 2.9$, the moisture content was $4.3 \pm 0.7-1.8 \pm 0.3 \%$, the weight loss was $17.76 \pm 1.3-19.02 \pm 0.9 \%$, Volume $40.7 \pm 2.1 \cdot 57.67 \pm 2.3 \mathrm{ml}$ the caffeine content was $2.39 \pm 0.1-2.38 \pm 0.2 \%$, the $\mathrm{pH}$ was $6.6 \pm 0.7-6.2 \pm 0.2$. The roasting levels affects on the physical chemical and spectra characteristic of roasted coffee.
\end{abstract}

Keywords: Coffee, physical-chemical properties, roasting levels, robusta, spectra IR,

\section{PENDAHULUAN}

Kopi merupakan komoditas kedua yang paling banyak diperdagangkan di dunia (Fareez Edzwan et al., 2015; Dias and Benassi, 2015, Jokanovica et al., 2012). Diantara varietas kopi, kopi arabika (Arabica) dan kopi canephora (Robusta) merupakan spesies terpenting yang paling banyak diperdagangkan di dunia (Dias and Benassi, 2015; ICO, 2020).

Provinsi Sumatera Selatan adalah Salah satu daerah penghasil kopi robusta, meliputi $20 \%$ dari total produksi kopi Robusta nasional. Sentra penghasil kopi di Sumatera Selatan tersebar di daerah Kabupaten Lahat, Muara Enim, Ogan Komering Ulu, Pagar Alam, Empat Lawang dan OKU Selatan, yang dikenal dengan nama kopi basemah, kopi empat lawang, kopi lahat, kopi Pagaralam dan kopi Semendo.

Kopi Semendo dihasilkan oleh Kecamatan Semende Darat Laut, Semende Darat Tengah, Semende Darat Ulu dan Kecamatan Tanjung Agung, pada ketinggian $600-1800$ mdpl. Ada dua jenis kopi yang diproduksi di kawasan ini yaitu kopi arabika dan kopi robusta. Kopi robusta ditanam di dataran rendah atau dibawah 1000 mdpl. Sebaliknya untuk Arabika lebih cocok di dataran tinggi diatas 1000 mdpl. Kopi Robusta Semendo telah memiliki sertifikat pengakuan indikasi geografis dari Kementerian Hukum dan Ham Indonesia. 
Indikasi geografis merupakan tanda yang digunakan pada barang yang memiliki asal geografis tertentu yang memiliki kualitas atau reputasi dimana kualitas tersebut dipengaruhi oleh asal barang tersebut ( March, 2007). Kopi Semendo memiliki cita rasa dan karakteristik kopi yang khas yang disebabkan goegrafis dan kandungan hara tanahnya. Paolo et al. (2016) dan Wang (2012) menyatakan bahwa asal geografis kopi membedakan kopi roasted dalam hal chemometric. Kopi roasted yang diroasting pada kondisi roasting yang sama dapat menghasilkan karakter yang berbeda. Perez-Sarinana dan Saldana Trinidad (2017) menyatakan bahwa kualitas biji kopi sangat dipengaruhi viabilitas, identitas kopi.

Kualitas kopi roasted sangat dipengaruhi oleh proses roasting. Proses roasting yang tidak terkendali akan menyebabkan kopi menjadi over roasted (gosong) atau kopi yang kurang matang yang akan menurunkan citarasa kopi. Rasa dan aroma seduhan kopi terbentuk selama roasting dimana biji kopi mengalami serangkaian reaksi kimia termasuk pembentukan senyawa volatil yang menyebabkan perubahan karakter fisika dan kimia (Farah, 2012; Fareez Edzuan et al., 2015).

Umumnya proses roasting dilakukan pada suhu lebih dari $200^{\circ} \mathrm{C}$, selama waktu tertentu, dan biasanya dikendalikan berdasarkan kehilangan berat dan perubahan warna (Chu et al., 2018). Craig et al. (2015) dan Wei dan Tanokura (2015) menyatakan bahwa karakter sensoris kopi roasted dan komposisi kimianya ditentukan oleh proses roasting.

Proses roasting merupakan proses perpindahan panas yang kompleks, dimana biji kopi mengalami penurunan berat secara konstan, peningkatan volume dan densitas, warna, pH, flavor, dan aroma (Fareez Edzuan et al., 2015; Noor Aliah et al., 2015). Serangkaian reaksi kimia juga terjadi meliputi reaksi Maillard, reaksi karamelisasi, pirolisis, dan oksidasi. Level roasting akan berpengaruh terhadap kualitas sensoris seperti warna, dan aroma seduhan kopi (Fareez Edzuan et al., 2015).

Level roasting dapat dipantau melalui warna, kehilangan berat, flavor dan aroma yang terbentuk akibat perubahan pada komponen kimia (Chu et al., 2018, Krol et al., 2020). Level roasting mempengaruhi zat yang terlarut dalam air (Diaz dan Benassi (2015). Lyman et al. (2003) menyatakan bahwa kopi yang diroasting pada level light roasted akan menghasilkan warna kopi yang tidak seragam dengan flavor asam, grassy dengan flavornya kurang berkembang. Kopi medium roasted memberikan keseimbangan yang baik antara aroma dan rasa dengan flavor citrus. Sebaliknya kopi dark roasted menghasilkan kopi dengan profil sensoris dengan keasaman rendah.

Penelitian tentang pengaruh roasting pada kopi telah banyak dilakukan, misalnya effect roasting on brewed coffee (Lyman et al., 2003), Pengaruh roasting, penyimpanan dan asal kopi terhadap kandungan polyphenol (Krol et al., 2020), perubahan sifat fisika kimia kopi Timor selama roasting (Fareez Edzuan et al., 2015), kopi Hararghe (Anisa et al., 2017), dan perubahan fisika kimia biji kopi selama roasting (Wang, 2012). Namun semua riset tersebut dilakukan pada sistim isothermal menggunakan oven atau roaster skala laboratorium, sehingga kondisi roasting dapat berbeda dengan sistim roasting yang sebenarnya. Riset ini mempelajari profil roasting, dan bagaimana level roasting dapat mempengaruhi sifat fisika dan kimia kopi roasted Semendo pada sistim yang sebenarnya dengan menggunakan roaster skala industry pada kondisi non isotermal. Oleh sebab itu tujuan dari penelitian ini adalah: a) untuk mempelajari profil roasting kopi robusta asal Semendo; b) untuk mempelajari sifat fisika kimia dan sensoris kopi roasted pada berbagai level roasting.

\section{BAHAN DAN METODE}

\section{Bahan}

Kopi yang digunakan pada penelitian ini adalah kopi Robusta asal Semendo yang disediakan oleh PD. Sahang Mas produsen kopi bubuk di kota Palembang. Kopi yang digunakan adalah kopi biji hasil fermentasi. Biji kopi di roasting menggunakan roaster (14 $\mathrm{kg} / \mathrm{batch})$ non isothermal, yang berbentuk drum berputar sehingga memungkinkan biji kopi dipanaskan secara menyeluruh, dan dilengkapi dengan monitor temperatur. Roaster juga memiliki kipas pendingin untuk mendinginkan kopi 
roasted. Warna kopi dapat dipantau menggunakan jendela pemantau, yang juga berfungsi sebagai titik sampling.

\section{Peralatan}

Peralatan untuk pengujian meliputi neraca analitik, oven, inkubator, FTIR, GCMS, pH meter, Konica color reader serta peralatan gelas yang diperlukan untuk analisa,

\section{Metode}

Rancangan penelitian yang digunakan dalam penelitian ini adalah rancangan acak lengkap (RAL) dengan level roasting sebagai perlakuan yaitu biji kopi belum diroasting ( $\mathrm{GB} / \mathrm{KB})$, first crack (FC)/Light Roasted(LR), second crack (SC)/Medium Roasted (MR), dan kopi roasted (KR/Dark Roasted (DR) pada suhu mencapai $5^{\circ} \mathrm{C}$ di atas suhu second crack). Pengamatan yang dilakukan adalah warna, kadar air, volume, densitas, kehilangan berat, $\mathrm{pH}$, kadar kafein, dan analisa chemometric (FTIR) kopi roasted.

Sebelum diroasting biji kopi $( \pm 10 \%$ moisture) dipanaskan di dalam roaster hingga suhu roaster mencapai $200^{\circ} \mathrm{C}$. Segera setelah itu biji kopi dimasukkan kedalam roaster, dan diroasting sampai didapatkan warna kopi sesuai dengan yang diinginkan. Umumnya waktu roasting adalah 40 menit. $100 \mathrm{gr}$ contoh diambil pada setiap level roasting \#1 (FC/LR), level \#2 (SC/MR), dan level \# 3 (KR/DR). Proses roasting akan diakhiri ketika suhu yang diinginkan telah dicapai. Kopi roasted segera dikeluarkan dari roaster, dan didinginkan sampai suhu $40^{\circ} \mathrm{C}$ untuk menghentikan proses roasting secara sempurna.

Warna dinalisa menggunakan Hunter lab color meter (Konica) color reader. Pembacaan warna menggunakan standar CIELAB terdiri dari L (lightness/ brightness;100 =putih, $0=$ hitam).

Kehilangan berat diukur berdasarkan perbedaan berat sampel (100 biji kopi) sebelum dan sesudah roasting. Volume diukur untuk 100 biji kopi dalam penerima $50 \mathrm{ml}$ dan densitas dihitung sebagai rasio antara berat dan volume 100 kopi biji. Kadar air diukur secara gravimetri (AOAC,
2016). Pengujian kadar kafein ditentukan menggunakan GCMS.

$\mathrm{pH}$ diukur menggunakan $\mathrm{pH}$ meter yang dilengkapi elektroda probe. Kopi bubuk (2g) dimasukkan dalam $200 \mathrm{~mL}$ beaker glass, dan ditambahkan $100 \mathrm{~mL}$ air deionisasi. Ekstrak yang telah disaring (50 $\mathrm{mL}$ ) digunakan untuk pengukuran $\mathrm{pH}$ menggunakan $\mathrm{pH}$ meter. Pengukuran dilakukan 3 kali.

Untuk mengetahui jenis ikatan kimia yang terkandung pada kopi roasted digunakan FT-IR Nicolet is 10 Thermo scientific, yang dilengkapi dengan Thermo Scientific Common Materilas and white Powder spectral Library. Sampel kopi biji dan kopi roasted dihaluskan menggunakan blender sebelum dilakukan analisa FTIR. Masing masing satu $g$ sampel setiap perlakuan di gunakan untuk analisa FTIR dan direkam pada panjang gelombang 4000-400 $\mathrm{cm}^{-1}$, dan dilakukan analisa visual terhadap spektra yang dihasilkan. Untuk menduga sifat sensoris kopi dilakukan perbandingan spektra dengan spektra yang tersedia pada Library of Common Materials pada wilayah panjang gelombang 3495,26-499,96 $\mathrm{cm}^{-1}$.

Semua hasil dinyatakan sebagai rerata dan standard deviasi dari 3 replikasi. Data dianalisa menggunakan program statistik SAS 9.1.3.

\section{HASIL DAN PEMBAHASAN}

Profil roasting kopi Robusta selama roasting dapat dilihat pada Tabel 1 , dimana suhu didalam roaster turun setelah biji kopi dimasukkan, dan segera meningkat kembali secara kontinyu. Hal ini disebabkan karena perpindahan panas antara biji kopi dan udara panas didalam roaster, sampai terjadi kesetimbangan, maka suhu di dalam roaster mulai meningkat (titik balik) secara kontinyu. Pada tahap ini kenaikan suhu berlangsung lambat karena terjadi penguapan air. Pada titik ini warna biji kopi berubah menguning, dan diikuti dengan pelepasan uap air sehingga terjadi penurunan kadar air. Segera setelah kadar air turun, suhu di dalam roaster meningkat dengan cepat dan proses pencoklatan, karamelisasi gula, dan reaksi lainya (reaksi Maillard, degradasi 
Strecker, Pirolisis) dimulai. Warna biji kopi berubah menjadi coklat. Pada tahap ini terjadi pelepasan gas, dimulainya pembentukan flavor, dan struktur kopi menjadi rapuh dan suara retakan terdengar (first crack) (Farah, 2012).

Tabel 1: Profil roasting kopi robusta semendo

\begin{tabular}{|c|c|c|c|c|c|c|}
\hline \multirow{2}{*}{$\begin{array}{c}\text { Inlet } \\
{ }^{\mathrm{T}} \\
\left({ }^{\circ} \mathrm{C}\right)\end{array}$} & \multicolumn{2}{|c|}{ First Crack } & \multicolumn{2}{|c|}{$\begin{array}{c}\text { Second } \\
\text { Crack }\end{array}$} & \multicolumn{2}{|c|}{ Akhir roasting } \\
\hline & $\mathrm{T}\left({ }^{0} \mathrm{C}\right)$ & $\mathrm{t}(\mathrm{m})$ & $\mathrm{T}\left({ }^{0} \mathrm{C}\right)$ & $\mathrm{t}(\mathrm{m})$ & $\mathrm{T}\left({ }^{0} \mathrm{C}\right)$ & $\mathrm{t}(\mathrm{m})$ \\
\hline 144 & 220 & 20 & 230 & 34 & 240 & 40 \\
\hline
\end{tabular}

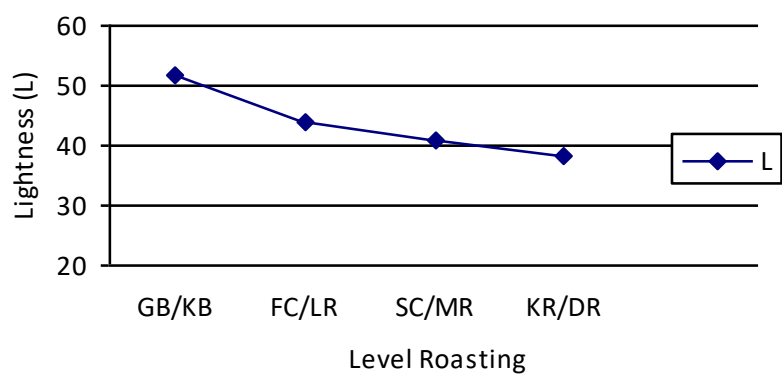

Gambar 1. Perubahan warna kopi selama roasting

Perubahan warna kopi selama roasting ditunjukkan oleh penurunan parameter $L^{*}$. Perubahan warna ini disebabkan karena reaksi pencoklatan non-enzymatis seperti reaksi Maillard, degradasi Strecker, karamellisasi, dan reaksi pirolisis, yang menyebabkan warna kopi berubah menjadi gelap. Hal ini sesuai dengan penelitian terdahulu yang menyatakan bahwa pencoklatan dan tingkat roasting pada kopi digambarkan oleh penurunan parameter $L^{*}$ (Wang, 2012; Jokanovic et al., 2012; Fareez Eduan et al., 2015; Anisa et al., 2017).

\begin{tabular}{|c|c|c|c|c|}
\hline & $\mathrm{GB} / \mathrm{KB}$ & FC/LR & SC/MR & KR/DR \\
\hline & $51,4 \pm 2,4^{a}$ & $42,10 \pm 2,7^{6}$ & $39,9 \pm 3,2^{b}$ & $38,14 \pm 2,9^{b}$ \\
\hline rat (g) & $24,2 \pm 0,9^{a}$ & $19,9 \pm 1,2^{b}$ & $19,7 \pm 0,8^{b}$ & $19,6 \pm 0,9^{b}$ \\
\hline $\mathrm{l}(\mathrm{ml})$ & $38,2 \pm 1,6^{b}$ & $40,7 \pm 2,1^{a}$ & $51,3 \pm 1,8^{b}$ & $57,67 \pm 2,3^{b}$ \\
\hline$(\%)$ & $9,6 \pm 0,4^{a}$ & $4,3 \pm 0,7^{b}$ & $2,16 \pm 0,6^{c}$ & $1,8 \pm 0,3^{d}$ \\
\hline & $6,7 \pm 0,2^{\mathrm{a}}$ & $6,6 \pm 0,7^{a}$ & $6,1 \pm 0,6^{b}$ & $6,2 \pm 0,2^{b}$ \\
\hline oi & $2,41 \pm 0,1^{a}$ & $2,39 \pm 0,1^{a}$ & $2,38 \pm 0,3^{a}$ & $2,38 \pm 0,2$ \\
\hline
\end{tabular}

Selama roasting, berat kopi menurun secara gradual. Hal ini disebabkan karena penguapan air dan pembentukan senyawa volatil (karbon dioksida dan senyawa aromatik) sebagai hasil dari reaksi kimia yang dilepaskan ke sekitar (Fareez Eduan et al., 2015; Anisa et al., 2017). Total kehilangan berat untuk kopi light roasted adalah $17,76 \pm 1,3 \%$, untuk medium roast $18,56 \pm 1,2 \%$ dan $19,02 \pm 0,9 \%$ untuk dark roasted. Hasil ini sesuai dengan beberapa studi lainnya yang menyatakan kehilangan berat selama roasting adalah $22 \%$ (Jokanovic et al., 2012), $28 \%$ (Fareez Eduan et al., 2015), 18.86 \% (Anisa et al., 2017). Hal ini berimplikasi kepada yield dan harga kopi. Yield kopi dark roasted < medium roasted < light roasted.

Perubahan volume kopi selama roasting mengindikasikan bahwa biji kopi mengembang sesuai kenaikan suhu pada biji kopi. Peningkatan volume disebabkan oleh penguapan air, pelepasan karbon dioksida dan senyawa volatil (Dutra et al., 2001; Hernandez et al., 2008). Pada level KR/DR, ukuran biji kopi meningkat sebesar $51,02 \%$. Uji beda menunjukkan pada level FC/LR volume kopi berbeda tidak nyata dengan volume $\mathrm{GB} / \mathrm{KB}$ dan berbeda nyata dengan level SC/MR dan KR/DR. Volume SC/MR berbeda tidak nyata dengan KR/DR. Hasil ini sesuai dengan hasil studi lainya yang menyatakan bahwa selama roasting volume biji kopi meningkat antara $15 \%$ hingga $70 \%$ (Jokanovic et al., 2012). Sebagai konsekwensi dari kehilangan berat dan peningkatan volume biji kopi, maka terjadi penurunan densitas kopi. Penurunan densitas menunjukkan terjadinya perubahan pada struktur kopi dimana terjadi peningkatan porositas sebagai hasil dari pelepasan gas yang terbentuk selama proses roasting. Perubahan densitas kopi akan berdampak pada ukuran kemasan, semakin kecil densitas semakin besar ukuran kemasan yang diperlukan. Artinya kopi yang diroasting sampai level dark roasted membutuhkan volume kemasan yang lebih besar dibandingkan dengan medium roasted dan light roasted. 


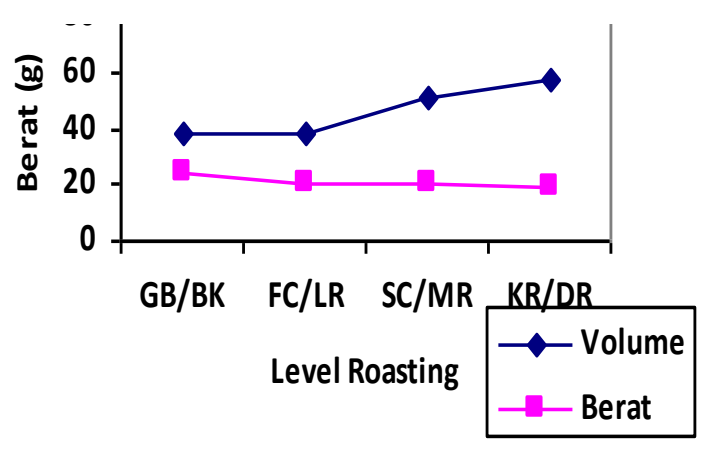

Gambar 2. Perubahan volume dan berat kopi

Selama proses roasting kadar air menurun karena terjadinya penguapan. Hal ini senada dengan penelitian yang dilakukan peneliti lainnya yang menemukan penurunan kadar air selama roasting (Chu et al., 2018). Hasil pengujian menunjukkan bahwa kadar air kopi pada semua level roasting kurang dari $5 \%$. Jika dikaitkan dengan persyaratan standar nasional (BSN, 2004) dan standar internasional kopi roasted mensyaratkan kadar air maksimum $5 \%$ pada saat pengemasan (Agustini dan Yusya, 2020), maka dapat disimpulkan bahwa pada level FC/LR $(L=44)$ telah memenuhi persyaratan standar kadar air. Kadar air yang rendah akan menghambat pertumbuhan mikroba dan tergolong aman secara mikrobiologis ( Agustini, 2018; Oktavia dan Agustini, 2019). Meskipun demikian Lyman et al. (2003) menyatakan bahwa kopi dengan level light roasted memiliki flavor yang belum berkembang, asam dan grassy.

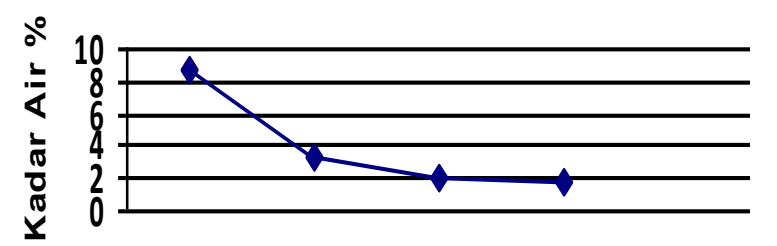

\section{GB/KB $\quad F C / L R \quad S C / M R \quad K R / D R$}

\section{Level Roasting}

Gambar 3. Penurunan kadar air

Hasil pengujian menunjukkan bahwa $\mathrm{pH}$ kopi robusta Semendo tergolong netral dan sedikit asam. Hal ini disebabkan karena biji kopi yang digunakan adalah biji kopi hasil proses fermentasi. Selama roasting, $\mathrm{pH}$ kopi robusta menurun dari 6,7 menjadi 6,1. Hasil ini berbeda dari studi lainya yang melaporkan peningkatan $\mathrm{pH}$ kopi seiring meningkatnya waktu roasting (Divis et al., 2019). pH kopi berhubungan erat dengan keasaman. $\mathrm{pH}$ seduhan kopi berasal dari berbagai asam seperti asam aliphatik, klorogenat, alisiklik, asam karboksilat (asam malat, asam sitrat, dan asam asetat) serta asam phenolat. Asam pada kopi mempunyai pengaruh signifikan pada kualitas sensoris seduhan kopi. Wang (2012) menyatakan bahwa keasaman kopi merupakan salah satu atribut yang berhubungan dengan kualitas kopi.

Kafein merupakan zat yang sangat penting pada kopi. Kadar kafein menentukan kekuatan, body, bitterness (rasa pahit), dan flavor dari seduhan kopi, serta memberikan indikasi terhadap mutu kopi. Kafein memiliki efek sebagai stimulan terhadap sistim syaraf, merelaksasi otot bronchial dan otot sekresi (Kinuthia et al., 2017; Perez-sarinana dan SaldanaTrinidad, 2017; Van Cuong et al., 2014; Nuhu, 2014; Farah, 2012). Hasil uji menunjukkan bahwa kadar kafein kopi robusta Semendo adalah 2,41\%. Hasil pengujian menunjukkan terjadi penurunan kadar kafein selama roasting, namun penurunan tersebut tidak signifikan. Pada spektra FTIR terlihat intensitas peak wilayah spektra kafein 1650-1600 $\mathrm{cm}^{1}$ untuk semua perlakuan relativ tidak berbeda. Hal ini sesuai dengan penelitian terdahulu yang menyatakan bahwa kadar kafein tertinggi didapat pada level light roasting, dan sedikit menurun jika roasting dilanjutkan (Hecimovic et al., 2011; Fuller dan Rao, 2017).

Gambar 4 menunjukkan transmisi spektra IR dari setiap jenis sampel. Analisis visual terhadap spektra IR pada setiap sampel kopi menunjukan adanya perbedaan karakter spektra pada setiap perlakuan. Perbedaan spektra tersebut dapat dilihat pada daerah sidik jari yaitu daerah 500-1500 $\mathrm{cm}^{-1}$ (Dachriyanus, 2004), dimana spektra GB/KB (508-1541 $\mathrm{cm}^{-1}$ ) lebih luas dibandingkan dengan FC/LR (505-1516 cm $\left.{ }^{-1}\right)$ SC/MR (501-1515 $\left.\mathrm{cm}^{-1}\right)$ dan KR/DR $\left(501-1515 \mathrm{~cm}^{-1}\right)$. Wilayah Spektra 2500-3300 $\mathrm{cm}^{-1}$ yang merupakan gugus $\mathrm{OH}$ asam (Dachriyanus, 2004) relativ tidak berbeda antara level roasting FC/LR $\left(2853,2922,3307 \mathrm{~cm}^{-1}\right), \quad$ SC/MR (2853, 2922,3307 $\mathrm{cm}^{-1}$ ) dan KR/DR (2853, 
2922, $\left.3307 \mathrm{~cm}^{-1}\right)$. Peak yang sama juga ditemukan pada $\mathrm{GB} / \mathrm{KB}$ namun dengan pola peak yang berbeda dan lebih sempit (2852, 2951, $\left.3291 \mathrm{~cm}^{-1}\right)$. Pada wilayah spektra lipida dan ester asam lemak (1600$1800 \mathrm{~cm}^{-1}$ ) pada FC/LR $\left(1646,1743 \mathrm{~cm}^{-1}\right)$, dan SC/MR $\left(1650,1743 \mathrm{~cm}^{-1}\right)$ lebih sempit dibandingkan dengan GB/KB $(1635,1743$ $\left.\mathrm{cm}^{-1}\right)$. Berbeda dengan level roasting lainya level KR/DR menunjukkan pola spektra berbeda yang ditunjukkan oleh 3 peak $\left(1651,1698,1743 \mathrm{~cm}^{-1}\right)$.
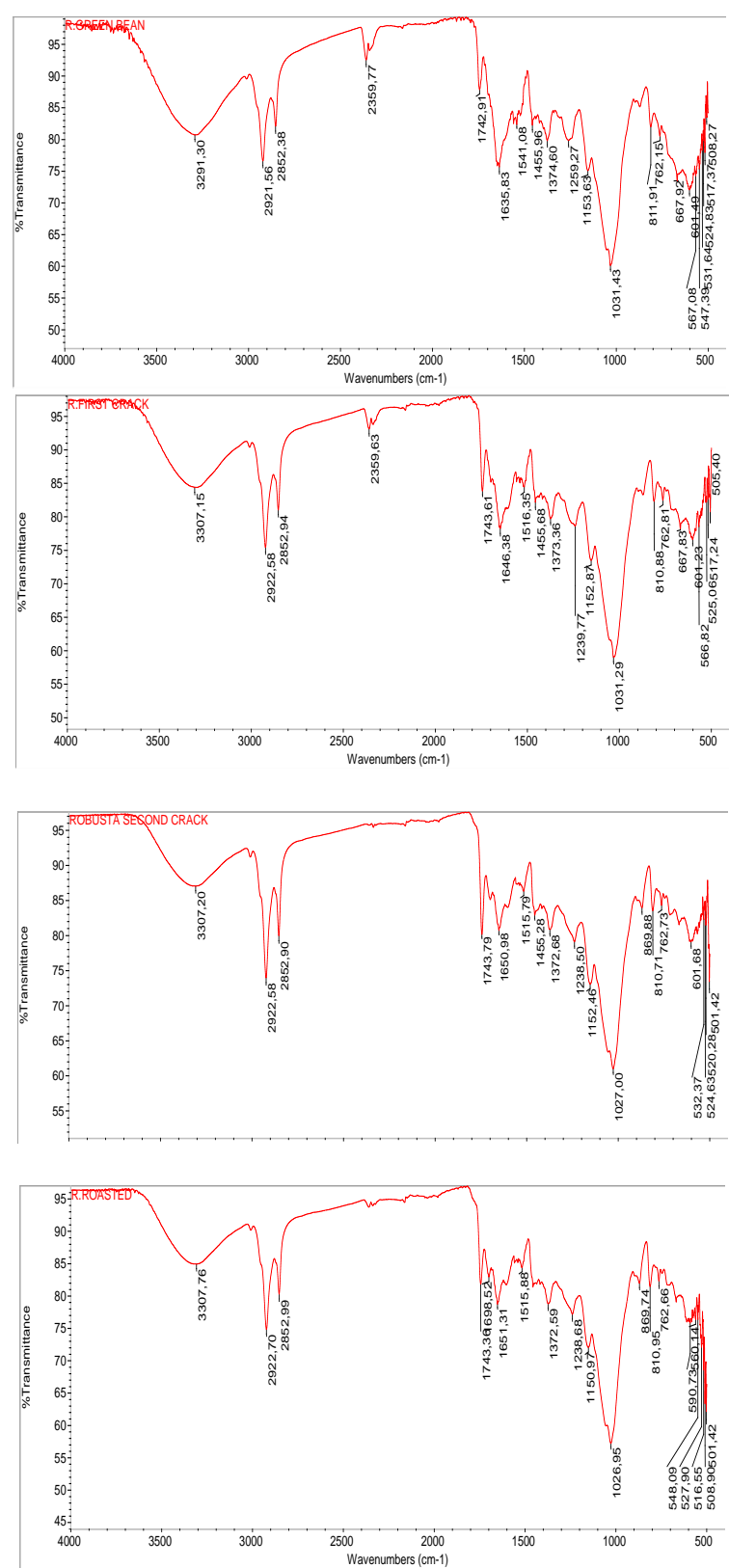

Gambar 4. Spektra IR GB/KB (paling atas), FC/LR (kedua dari atas), SC/MR (ketiga dari atas) dan KR/DR (paling bawah)
Analisis korelasi spektra IR kopi hasil perlakuan dengan spektra IR pada library common materials pada wilayah spektra 3495-499,96 cm $\mathrm{cm}^{-1}$, menunjukkan terjadinya pergeseran sifat sensoris kopi selama proses roasting. Spektra kopi biji (GB/BK) memiliki kecocokan dengan spektra coffee ground caffeinated $(75,51 \%)$. Kopi yang di roasting hingga level FC/LR memiliki kecocokan spektra yang mirip dengan coffee ground caffeinated (85,51\%). Hasil ini menunjukkan bahwa kemiripan spektra kopi $G B / K B$ masih terlihat pada spektra FC/LR hanya berbeda pada intensitas nya, misalnya pada GB/KB kecocokan dengan ground coffee cafeinated hanya $75,51 \%$, setelah roasting hingga level FC/LR kecocokannya menjadi 85,51\%. Kecocokan spektra kopi pada level SC/MR dan KR/DR mirip dengan $\mathrm{FC} / \mathrm{LR}$ dengan tingkat kecocokan yang berbeda. Misalnya kopi pada level SC/MR memiliki kecocokan dengan spektra coffee ground caffeinated paling tinggi $(88,76 \%)$ dibandingkan dengan kopi pada level FC/LR (85,51\%) dan KR/DR (77,76\%). Hal ini sesuai dengan Wang (2012) dan Paolo et al. (2016) yang menyatakan bahwa asal geografis kopi membedakan kopi roasted dalam hal chemometric. Selain itu perbandingan spektra ini juga menunjukkan adanya pengaruh roasting terhadap sifat sensoris kopi yang dihasilkan. Artinya kopi yang diroasting pada level yang berbeda akan memberikan sifat sensoris yang berbeda. Hal ini ditunjukkan oleh kecocokan spektra kopi SC/MR dengan lechitin (72,99) dan coenzym Q-10 $(68,32 \%)$ yang tidak ditemukan pada level FC/LR maupun KR/DR. Begitu juga kecocokan spektra dengan red pepper seed dan spanish safron yang ditemukan pada level FC/LR dan KR/DR tidak ditemukan pada level SC/MR.

\section{KESIMPULAN}

Hasil penelitian menunjukkan bahwa terjadi perubahan sifat fisika kopi selama roasting seperti, kadar air, volume, dan densitas, $\mathrm{pH}$ serta chemometric (spektra IR) kopi. Selama roasting terjadi kehilangan berat, peningkatan volume, penurunan densitas, kadar air, $\mathrm{pH}$ dan kadar kafein kopi serta 
perubahan chemometric kopi. Level roasting berpengaruh terhadap sifat fisika kimia kopi roasted yang dihasilkan. Pemilihan level roasting yang cocok yang akan menghasilkan kopi roasted dengan kualitas yang baik, sangat penting bagi industri pengolah kopi.

\section{UCAPAN TERIMA KASIH}

Penulis mengucapkan terima kasih Kepala Balai Riset dan standardisasi Industri Palembang dan PD. Sahang Mas yang telah memfasilitasi penelitian ini.

\section{DAFTAR PUSTAKA}

Agustini, S (2018). The Characterization of Mango (Mangifera Indica L) Powder of Various drying Temperature. Journal of Physics: Conf.Series 1095(2018) 012035.

Agustini, S dan Yusya, M.K (2020). The Effect of Packaging Materials on the Physicochemical Stability of Ground Roasted Coffee. Current Research on Bioscience and Biotechnology 1(2):66-70.

Andayani, O dan Agustini, S (2019). Penentuan Masa Simpan Kopi Bubuk Dalam Kemasan Aluminium Laminated Polyetilen (ALP) dan Polyetilen Ptalat (PET). Jurnal Dimanika Penelitian Industri 30(2):148-153.

Anisa, A., Solomon, W.K., and Solomon, A. (2017). Optimiztion of roasting time and temperature for brewed hararghe coffee (Coffea Arabica L) using central composite design International Food Research Journal, 24(6): 2285-2294.

AOAC.(2016). Association of Official Analytic Chemist. Official Methods of Analysis of AOAC International (16 th Ed) Gaithersburg MD, USA: AOAC International.

Badan Standardisasi Nasional (2004). Kopi Bubuk. SNI 3542-2004. Jakarta.

Chu, B., Yu, K., Zhao, Y., He, Y. (2018). Development of non invasive Classification Methods for Different Roasting Degrees of Coffee Beans Using Hyper Spectral Imaging.
Sensor (Basel) 18(4):1259. doi:10.3390/s18041259

Craig, A.P., Franca, A.S., Oliveira, L.S., Irudayaraj, J., Ileleji, K. (2015). Fourier transform infrared spectroscopy and near infrared spectroscopy for the quantification of defects in roasted coffees. Talanta, 134: 379-386.

Dachriyanus (2004). Analisis Struktur Senyawa Organik Secara Spektroskopi. LPTIK Universitas Andalasis. P 21-37.

Dias, R.C.E and Benassi, M.T. (2015). Discrimination between Arabica and Robusta Coffees Using Hydro-soluble Compounds: Is the Efficiency of the Parameters Dependent on the Roast Degree. Beverages, 1: 127-139.

Divis, P., Porizka, J., dan Krikala, J. (2019). The Effect of Coffee Beans Roasting on Its Chemical Composition. Potravinarstvo Slovak Journal of Food Sciences 13(1): 344-350. https://doi.org/10.5219/1062

Farah, A. (2012). Coffee Constituent in Chu, Y. Coffee: Emerging Health Effects and Disease Prevention, John Wiley \& Sons, Inc. Published 2012 by Blackwell Publishing Ltd, First Edition.

Fareez Edzuan A.M., Noor Aliah, A.M., Bong, H.L. (2015). Physical and Chemical Property Changes of Coffee Beans during Roasting. American Journal of Chemistry,5(3A): 56-60.

Fuller, M dan Rao, N.Z. (2017). The Effect of Time, Roasting Temperature, and Grind Size on Caffeine and Chlorogenic Acid Concentration in Cold Brew Coffee. Scientific Reports 7:17979.DOI:10.1038/s41598-01718247-4

Hecimovic, I., Belscak-Cvitanovic, A., Horzic, D., dan Komes, D. (2011). Comparative study of Polyphenols and Caffeine in Varieties Affected by Degree of Roasting. Food Chem, 129(3):991-1000. doi: 10.1016/j.foodchem.2011.05.059. Epub 2011 May 15

ICO (International Coffee Organization), 2020. Total production by all 
exporting countries. , Retrieved on January 2020, from ICO website: http://www.ico.org/price/production table.pdf (accessed on March 2020).

International Coffee Organization. 2018. ICC 122-12. National Coffee Standard. London United Kingdom.

Jokanovića,M.R.,Džinića,N.R.,Cvetković,B. R., Grujićc. S and Odžaković,B. (2012). Changes Of Physical Properties Of Coffee Beans During Roasting. APTEFF., 43:21-31.

Krol, K., Gantner, M., Tatarak, A dan Hallmann, E. (2020). The Content of Polyphenols of Coffee Beans as Roasting, Storage and Origin Effect. Europian Food Research and Technology 246:33-39.

Lyman, D.J., Benck, R., Dell, S., Merle, S., and Murray-Wijelath.J. (2003). FTIRATR Analysis of Brewed Coffee ; Effect of Roasting Condition. Journal of Agricultural and Food Chemistry, 51(11):3268-3272.

March, E. (2007). Geographical Indications: From Darjeeling to Doha, WIPO Magazine Editor, July 2007. http://www.wipo.int/wipo_magazine/e n/2007/04/article 0003.html

Noor Aliah, A.M., Fareez Edzuan, A.M., Noor Diana, M. (2015). "A Review of Quality Coffee Roasting Degree Evaluation", Journal of Applied Science and Agriculture, 10(7):18-23.

Nuhu, A.A. (2014). Bioactive Micronutrients in Coffee: Recent Analytical Approaches for Characterization and Quantification. ISRN Nutrition: 1-13.

Paulo R.A.B. Toledo, Leonardo Pezza, Helena R. Pezza, and Aline T. Toci (2016). Relationship Between the Different Aspects Related to Coffee Quality and Their Volatile Compounds. Comprehensive Reviews in Food Science and Food Safety, 15:705-719.

Pérez-Sariñana, B.Y., and SaldañaTrinidad, S. (2017). Chemistry and Bio transformation of Coffee ByProducts to Bio fuels in The Question of Caffeine.

Van Cuong, T., Hong Ling, L., Kang Quan, G., Jin, S., Shu Jie, S., Le Linh, T., and Duc Tiep, T. (2014). Effect of roasting condition on concentration in elements of Vietnam robusta coffee, Acta Universitatis Cibiniensis Series E: Food Technology, 17(2): 19-34.

Wang, N (2012). Physicochemical Changes of Coffee Beans During Roasting. Thesis. University of Guelph.

Wei, F.; Tanokura, M. (2015). Chemical changes in the components of coffee beans during roasting. In Preedy, V.R. Coffee in Health and Disease Prevention, Academic Press-Elsevier: London, UK, 1st edition.

http://www.coffeeresearch.org/science/sour main.htm 